\title{
PENGETAHUAN DAN PENGARUHNYA TERHADAP PERILAKU BERLALU LINTAS; TINJAUAN TERHADAP PELAKU LALU LINTAS USIA REMAJA DI SMK YPT 1 PURBALINGGA
}

\section{Knowledge and Effects on Traffic Behavior; Review of Adolescent Traffic Perpetrators in SMK YPT 1 Purbalingga}

\author{
Probo Hardini \\ Jurusan Teknik Sipil, Fakultas Teknik \\ Universitas Jenderal Soedirman \\ Jl. Mayjen. Sungkono Km 5, Kalimanah, \\ Purbalingga, Jawa Tengah \\ probo.hardini@unsoed.ac.id
}

\author{
Eva Wahyu Indriyati \\ Jurusan Teknik Sipil, Fakultas Teknik \\ Universitas Jenderal Soedirman \\ Jl. Mayjen. Sungkono Km 5, Kalimanah, \\ Purbalingga, Jawa Tengah \\ eva.indriyati@unsoed.ac.id
}

\begin{abstract}
The casualties in the teenage group in Purbalingga Regency averaged $21.25 \%$ of the total accident victims in this area. This relatively large proportion requires efforts through various approaches to reduce the high number of accidents, considering that this group of age is a very important period in people's growth process. This study aims to identify the effect of traffic knowledge on teenage traffic behaviour taking SMK YPT 1 Purbalingga as the case study location. In its analytical process, this research uses descriptive quantitative analysis methods and logistic regression analysis. The output of logistic regression using realstatistic software, identified that the ownership of the driving license provides an opportunity for the occurrence of a bad traffic behaviour. In addition, the better knowledge about signs will provide a role for the possibility of good traffic behaviour. Moreover, the low understanding of road marking gives a probability of bad traffic behaviour.
\end{abstract}

Keywords: accident, traffic behaviour, teenage

\begin{abstract}
Abstrak
Korban kecelakaan pada kelompok usia remaja di Kabupaten Purbalingga rata-rata sebesar 21,25\% dari total korban kecelakaan di daerah ini. Proporsi yang relatif besar ini memerlukan upaya-upaya melalui bermacam pendekatan untuk menekan tingginya angka kecelakaan pada kelompok usia ini, mengingat usia remaja adalah usia yang sangat penting dalam proses tumbuh kembang seseorang. Penelitian ini bertujuan untuk mengidentifikasi pengaruh pengetahuan lalu lintas terhadap perilaku pelaku lalu lintas usia remaja. Dalam prosesnya, penelitian menggunakan metode analisis kuantitatif deskriptif dan analisis regresi logistik. Luaran perhitungan regresi logistik dengan bantuan software realstatistic, diidentifikasi bahwa tidak memiliki SIM memberikan peluang untuk terjadinya perilaku berlalu lintas yang tidak baik. Selain itu, pengetahuan tentang rambu yang semakin baik akan memberikan peranan terhadap kemungkinan perilaku berlalu lintas yang baik. Pada usia remaja, pengetahuan tentang marka yang rendah memberikan probabilitas munculnya perilaku berlalu lintas yang tidak baik.
\end{abstract}

Kata kunci: kecelakaan, perilaku berlalu lintas, usia remaja 


\section{LATAR BELAKANG}

Berdasarkan data kecelakaan dari IRSMS dalam lima tahun terakhir (2013 - 2018) jumlah korban kecelakaan usia remaja ${ }^{1}$ di wilayah pelayanan Kepolisian Resor Purbalingga ratarata mencapai $21,25 \%$ terhadap kelompok-kelompok usia korban yang lainnya. Persentase ini menempati angka tertinggi pada tahun 2018 yang sebesar 23,41\% (IRSMS Polri, 2018). Melihat besaran jumlah korban kecelakaan lalu lintas ini, diperlukan upaya-upaya melalui bermacam pendekatan diperlukan untuk menekan tingginya angka kecelakaan pada kelompok usia ini, mengingat usia remaja adalah usia yang sangat penting dalam proses tumbuh kembang seseorang.

Perilaku dan kesadaran untuk mematuhi peraturan lalu lintas berperan di dalam terciptanya lalu lintas yang aman dan lancar di jalan. Perilaku berkendara dari pengguna jalan merupakan bagian yang tidak terpisahkan dari suatu sistem transportasi. Walaupun demikian, aspek ini sering terabaikan dalam tinjauan sistem transportasi. Dalam kajian studi transportasi, perilaku berkendara pengguna perjalanan memberikan kontribusi yang besar dalam terselenggaranya sistem transportasi. Sucha (2014) menyebutkan bahwa perilaku pengendara ini mengoptimalisasi sistem transportasi dalam memenuhi permintaan transportasi dengan kerusakan yang minimum. Dengan demikian, perilaku berkendara yang baik akan berdampak pada terciptanya sistem transportasi yang handal.

Penelitian dari Pangestika (2016) menemukan bahwa perilaku berkendaraan berkaitan dengan keselamatan lalu lintas. Hal ini direpresentasikan dengan jumlah kecelakaan yang berkorelasi positif dengan buruknya perilaku berlalu lintas tersebut. Penelitian terhadap perilaku berkendaraan dan keselamatan berlalu lintas sudah banyak dilaksanakan. Walaupun demikian penelitian ini memberikan gambaran baru mengenai tingkat pengetahuan pengguna lalu lintas usia remaja terhadap pemahaman dan perilakunya. Oleh karenanya kegiatan penelitian ini bertujuan untuk: (1) Mengetahui karakteristik pengguna lalu lintas berusia remaja di lokasi studi, dan (2) Mengidentifikasi pengaruh pengetahuan berperilaku lalu lintas terhadap perilaku lalu lintas pengguna lalu lintas usia remaja.

\section{METODOLOGI}

\section{Lokasi Penelitian}

Penelitian dilakukan dengan sasaran pengguna lalu lintas usia remaja. Dengan pertimbangan pengguna kendaraan bermotor roda dua yang diasumsikan mempunyai persentase yang relatif besar maka penelitian dilakukan terhadap siswa SMK yang berlokasi di kawasan Kota Purbalingga. SMK terpilih adalah SMK YPT 1 Purbalingga.

\section{Data}

Kebutuhan data penelitian meliputi data sekunder dan data primer. Data sekunder berupa:

1. Data jumlah siswa aktif di lokasi penelitian yang diperoleh dari data siswa SMK YPT 1 Purbalingga.

2. Data kecelakaan dan korelasi usia pengguna lalu lintas terhadap tingkat kecelakaan. Data ini diperoleh dari data kecelakaan kepolisian dan artikel.

\footnotetext{
${ }^{1}$ Kelompok usia remaja menurut Departemen Kesehatan RI dibagi menjadi kelompok remaja awal yaiu untuk usia 12 s.d. 16 dan kelompok remaja akhir antara usia 17 s.d. 25 tahun (Depkes RI, 2008)
} 
Sedangkan data primer diperoleh dari pengisian kuisioner terhadap responden.

\section{Populasi dan sampel}

SMK YPT 1 Purbalingga mempunyai total siswa sebanyak 1052. Dengan menggunakan rumus Slovin dan pertimbangan homogenitas/heterogenitias populasi, sampel minimal yang dibutuhkan dapat ditentukan melalui persamaan:

$$
n=\frac{N}{1+N e^{2}}
$$

Dimana: $\mathrm{n}$ : jumlah sampel minimal

$\mathrm{N}$ : jumlah populasi

e : standar error (diambil 5\% dengan pertimbangan homogenitas populasi)

Menggunakan persamaan 1, diperoleh jumlah sampel minimal sebesar 161 siswa.

\section{Alat survei}

Survei primer seperti disebutkan sebelumnya menggunakan kuisioner. Model kuisioner yang diberikan adalah kuisioner tertutup. Beberapa aspek yang akan masuk dalam pertanyaan adalah:

1. Jenis kelamin

2. Moda yang digunakan

3. Jika menggunakan moda kendaraan bermotor roda dua, apakah sebagai pengemudi atau penumpang

4. Kepemilikan Surat Izin Mengemudi

5. Pengetahuan tentang marka dan rambu

6. Perilaku berlalu lintas terkait dengan peraturan, marka, rambu, dan APILL

\section{Alur Penelitian}

Titik awal pemikiran dari penelitian ini adalah kecelakaan lalu lintas pada kendaraan bermotor dan banyaknya pengendara sepeda motor dalam usia remaja. Kondisi ini menjadi pertimbangan di dalam identifikasi karakteristik pengguna lalu lintas usia remaja. Usia remaja mempunyai karakteristik psikologi khusus yang mempengaruhi pada sikap diri dan kemudian akan terwujud di dalam perilaku mereka di dalam berlalu lintas (Wåhlberg, 2011). Berdasarkan konsep dasar tentang perilaku, perilaku merupaan muara dari sikap dasar seseorang, pengetahuan, dan motivasi. Oleh karenanya, dengan melihat karakteristik pengendara lalu lintas usia remaja dan pengetahuan yang mereka punyai serta bagaimana pengendara dalam usia ini berperilaku di dalam berlalu lintas menjadi masukan untuk melakukan analisis pengaruh pengetahuan tersebut terhadap perilaku remaja dalam berlalu lintas. Secara diagramatis alur pemikiran penelitian disajikan dalam Gambar 1.

\section{Metode Analisis}

Data yang diperoleh nantinya akan dikompilasi dan ditabulasikan untuk selanjutnya dianalisis. Penganalisisan data dilakukan untuk mencapai tujuan dari penelitian. Di dalam penelitian ini analisis yang akan dilakukan meliputi analisis karakteristik dan analisis pengaruh pengaruh pengetahuan perilaku berlalu lintas terhadap perilaku berlalu lintas pada anak usia remaja. 
1. Analisis karakteristik

Karakteristik adalah ciri atau keunikan yang dimiliki oleh suatu. Analisis karakteristik bertujuan untuk mengidentifikasi dan mendeskripsikan obyek studi dalam penelitian. Menggunakan obyek studi pengendara usia remaja dalam hal ini, maka analisis karakteristik diharapkan akan menghasilkan luaran berupa bagaimana persebaran penggunaan moda sepeda motor di kalangan populasi penelitian. Lebih lanjut, pengguna dalam hal ini juga akan diklasifikasikan dalam proporsi penumpang dan pengendara. Selain itu, melalui analisis karakteristik juga akan diidentifikasikan bagaimana tingkat kepatuhan mereka terhadap aturan dasar penggunaan kendaraan roda dua, khususnya kepemilikan Surat Ijin Mengemudi dan pengunaan helm.

Dalam melakukan analisis ini maka digunakan pendekatan kuantitatif deskriptif. Pendekatan ini dilaksanakan dengan dua arah pandang, yaitu kuantitatif dan deskriptif. Sudut pandang kuantitatif dengan melihat data angka. Data angka tersebut kemudian akan didekati secara statistik deskriptif yang nantinya akan mengolah data dalam bentuk tabel dan grafik untuk membantu penyusunan kesimpulan.

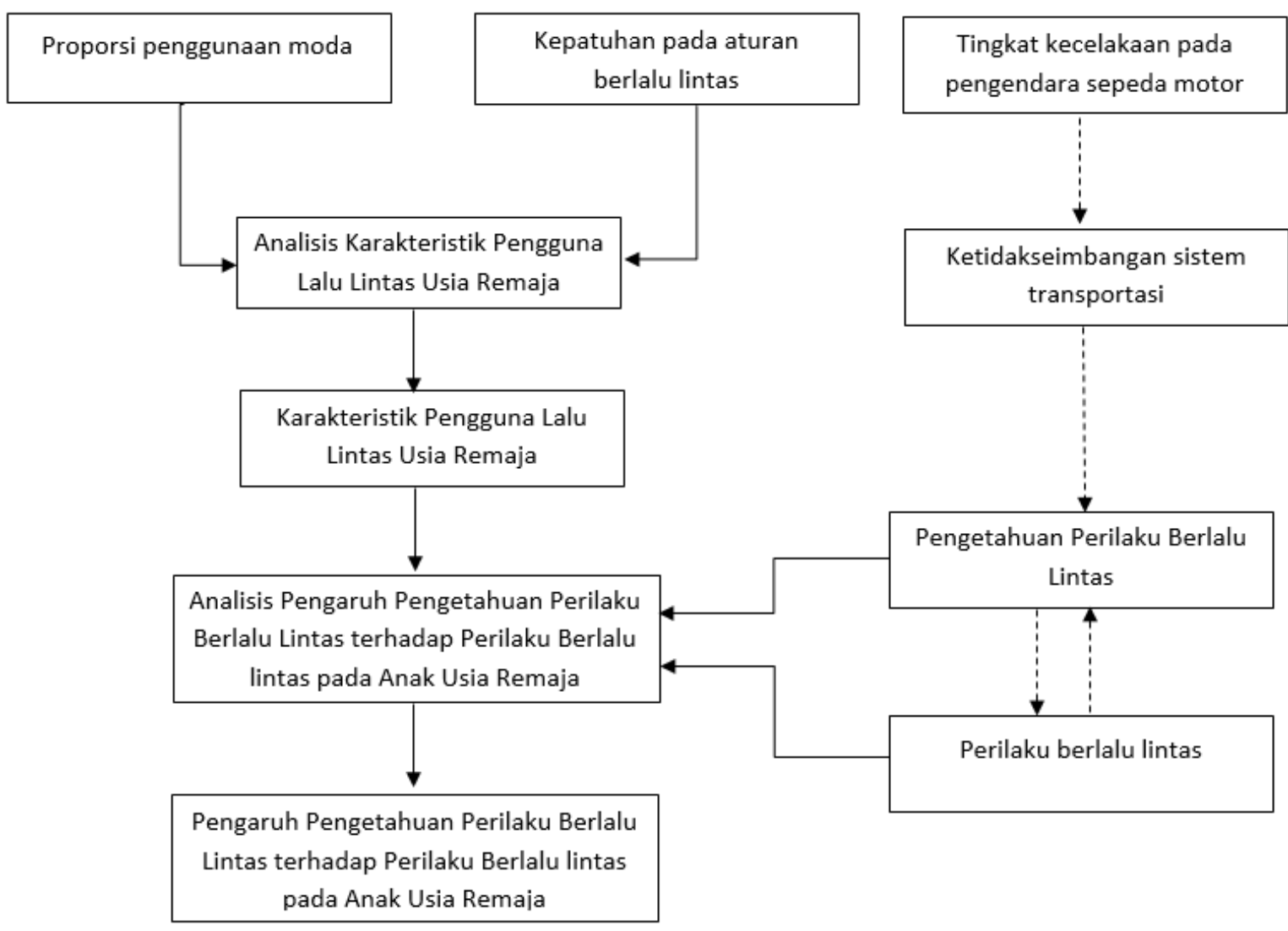

Gambar 1. Alur pemikiran

2. Pengaruh pengetahuan perilaku berlalu lintas terhadap perilaku berlalu lintas pada anak usia remaja

Analisis pengaruh ini dilakukan untuk mengetahui bagaimana pengetahuan tentang berlalu lintas yang baik dan benar memberikan pengaruh terhadap perilaku berlalu lintas pada remaja. Alat analisis yang digunakan adalah regresi logistik. Regresi logistik pada dasarnya adalah alat analisis yang bertujuan untuk mengetahui hubungan antara variabel terikat dan variabel bebas. Di dalam analisis ini, variabel terikat adalah 
pengetahuan berlalu lintas, sedangkan variable tidak terikatnya adalah perilaku berlalu lintas.

Menggunakan regresi logistik juga memungkinkan untuk menghubungkan antara satu atau beberapa variabel bebas dengan variabel tak bebasnya yang biasanya berupa kategori. Jenis variabel tak bebas yang berbentuk kategori inilah yang pada dasarnya membedakan regresi logistik dengan regresi linear jenis lainnya.

Variabel terikat dalam regresi logistik berbentuk biner (dikotomus). Variabel ini mengambil nilai 0 atau 1 . Nilai 0 mempunyai kemungkinan sukses $\Pi$ dan nilai 1 mempunyai kemungkinan kegagalan 1- П. Regresi logistik menggunakan beberapa asumsi, yaitu:

a. Data tidak harus berdistribusi normal

b. Data tidak harus mempunyai hubungan linear atau memiliki ragam yang sama dalam masing-masing kelompok

c. Hubungan antara varibel prediktor dan variabel respon bukanglah suatu fungsi linear

Ada beberapa tujuan yang akan dicapai dengan menggunakan metode regresi logistik, antara lain:

a. Mengetahui perbedaan karakteristik antar kelompok. Untuk melihat perbedaan ini, maka nilai odds ratio menjadi kajian yang penting untuk dijadikan materi interpretasi.

b. Mengetahui faktor-faktor yang mempengaruhi perbedaan antar kelompok

Regresi logistik memiliki persamaan:

$$
\ln \left(\frac{\hat{p}}{1-\hat{p}}\right)=B_{0}+B_{1} X
$$

Dengan:

$$
\hat{p}=\frac{\exp \left(B_{0}+B_{1} X\right)}{1+\exp \left(B_{0}+B_{1} X\right)}=\frac{e^{B_{0}+B_{1} X}}{1+e^{B_{0}+B_{1} X}}
$$

\section{PUSTAKA}

Sistem adalah suatu bentuk keterkaitan antar variabel atau komponen yang saling mendukung untuk mewujudkan tujuan dari sistem tersebut. Sedangkan transportasi adalah perpindahan, baik penumpang ataupun barang, dari satu tempat ke tempat yang lainnya. Jadi di dalam transportasi terdapat unsur motivasi dan perpindahan yang secara fisik direpresentasikan dalam bentuk perpindahan tempat baik dengan menggunakan ataupun tanpa alat angkut. Berdasar kedua pengertian tersebut, maka sistem transportasi dapat diartikan sebagai suatu bentuk keterikatan dan saling ketergantungan (interdependency) antar variabel untuk terjadinya perpindahan dari satu tempat ke tempat yang lainnya dengan aman dan nyaman. Dalam sistem transportasi, oleh karenanya, akan terdapat unsurunsur aktivitas, pergerakan, jaringan, dan pengelolaan yang saling pengaruh mempengaruhi (Sussman, 2000).

Saat ini transportasi menjadi bagian yang tak terpisahkan dari kehidupan manusia dengan semakin beragamnya aktivitas. Kondisi ini berpengaruh terhadap kebutuhan pemenuhan sarana atau moda transportasi. Terlebih lagi manusia semakin dituntut untuk bergerak dengan cepat dan efisien dari satu tempat ke tempat yang lainnya yang kemudian berdampak pada pemilihan moda dan pertumbuhan jumlah moda lalu lintas. 
Salah satu aspek yang terintegrasi dengan terlaksananya sistem transportasi adalah perilaku berlalu lintas (traffic behaviour). Menurut Evans (2004), perilaku berlalu lintas mencakup dua pengertian; yaitu performa pengendara dan perilaku pengendara. Performa pengendara terkait dengan pengetahuan, ketrampilan, persepsi, dan kemampuan kognitif. Sedangkan perilaku pengendara merujuk pada pilihan pengendara untuk melakukan atribut-atribut di performa tersebut. Jadi jelas di sini ada unsur pengetahuan dan kemampuan pengendara dan pilihan untuk melakukannya.

Unsur pengendara menjadi hal penting yang akan mempengaruhi performa dan perilaku mereka di jalan raya. Secara psikologis usia remaja, terutama remaja-remaja awal, adalah tahapan ketiga seseorang berusaha menemukan jati dirinya. Oleh karenanya di usia ini emosi akan cenderung meledak-ledak dan cenderung akan sangat cepat untuk menyerap reaksi orang di sekitarnya untuk menjadi pengalamannya di dalam menentukan tindakan bagi dirinya kelak di kemudian hari (Sarwono, 2011). Pemahaman, pengetahuan, dan bimbingan yang baik tentang bagaimana cara berlalu lintas yang baik pada tahapan usia ini dengan demikian akan sangat bermanfaat untuk terciptanya generasi yang taat dan berdisiplin dalam berlalu lintas.

\section{HASIL DAN PEMBAHASAN}

\section{Karakteristik Dasar Siswa SMK YPT 1 Purbalingga}

SMK YPT 1 Purbalingga adalah salah satu sekolah menengah kejuruan yang ada di Kabupaten Purbalingga. Berdiri pada tahun 1964, sekolah ini terus berkembang dengan jumlah siswa yang relatif stabil, terutama untuk ukuran sekolah kejuruan milik swasta seperti disajkan dalam Tabel 1.

Tabel 1. Jumlah siswa SMK YPT 1 Purbalingga

\begin{tabular}{cccccc}
\hline & \multicolumn{4}{c}{ Jumlah siswa (orang) } \\
\cline { 2 - 5 } & Laki-laki & $\%$ & Perempuan & $\%$ & Total \\
\hline Kelas 10 & 410 & $96.70 \%$ & 14 & $3.30 \%$ & 424.967 \\
\hline kelas 11 & 265 & $97.43 \%$ & 7 & $2.57 \%$ & 272.9743 \\
\hline Kelas 12 & 346 & $97.74 \%$ & 8 & $2.26 \%$ & 354.9774 \\
\hline Total & 1021 & $97.24 \%$ & 29 & $2.76 \%$ & 1052.919 \\
\hline
\end{tabular}

Sumber: Dapo Dikdasmen Kab. Purbalingga, 2018

Lokasinya yang strategis menjadikan sekolah ini menjadi rujukan bagi calon siswa yang datang bukan saja dari wilayah Kabupaten Purbalingga, tetapi juga dari wilayah Barlingmascakeb (Banjarnegara, Purbalingga, Banyumas, dan Kebumen). Berdasarkan hasil survei pendahuluan dengan menggunakan sampel 164 responden siswa, moda yang digunakan untuk bersekolah terbagi menjadi lima: (1) jalan kaki, (2) sepeda, (3) membonceng sepeda motor, (4) pengendara sepeda motor, dan (5) angkutan umum. Pilihan moda siswa mayoritas adalah pengendara sepeda motor yang mencapai $66 \%$ dari total jumlah responden seperti disajikan dalam Gambar 1. 


\section{Traffic Accident Research Centre}

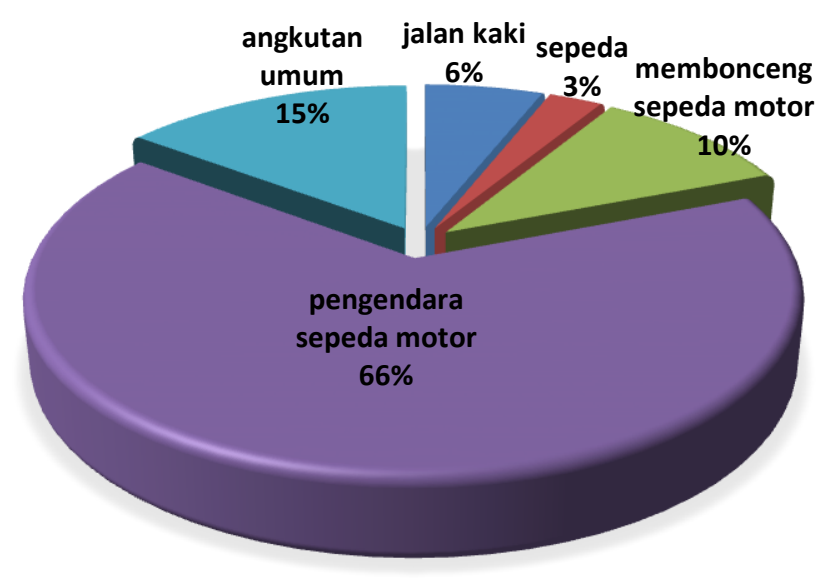

Gambar 2. Distribusi jenis moda yang digunakan

Besaran distribusi pengendara sepeda motor, walaupun demikian tidak sebanding dengan kepemilikan Surat Ijin Mengemudi yang merepresentasikan kesadaran dasar mematuhi peraturan. Sebesar $85,12 \%$ pengendara sepeda motor di SMK YPT 1 Purbalingga terdata belum memiliki SIM. Gambar 2 menyajikan persebaran kepemilikan SIM diantara siswasiswa pengendara sepeda motor.

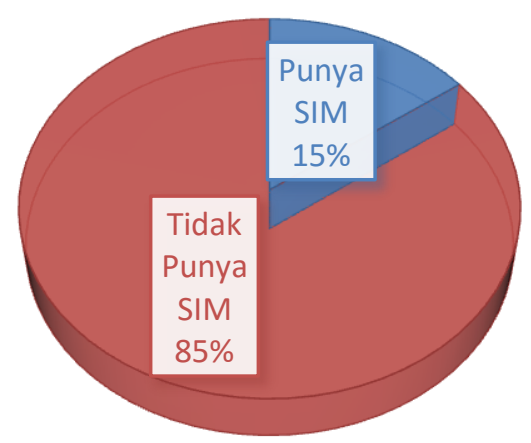

Gambar 3. Distribusi kepemilikan SIM pada siswa SMK YPT 1 Purbalingga

\section{Analisis Regresi Logistik}

Analisis regresi logistik pada dasarnya dilakukan untuk menentukan probabilitas perilaku berlalu lintas dari pengguna jalan, dalam hal ini adalah siswa SMK YPT 1 Purbalingga sebagai sampel pengguna usia remaja. Variabel bebas meliputi: (1) kepemilikkan SIM, (2) pengetahuan tentang rambu, (3) pengetahuan tentang marka. Sedangkan variabel tidak bebas adalah perilaku berlalu lintas yang terkategorikan menjadi perilaku baik, dikodekan dengan 1, dan perilaku tidak baik yang dikodekan dengan 0 .

Penggunaan kuisioner membantu untuk memprediksikan perilaku berlalu lintas responden. Terkait dengan perilaku, pertanyaan berhubungan dengan bagaimana tindakan yang diambil ketika responden bertemu dengan variabel bebas nomor (2) dan (3). Berdasarkan hasil analisis regresi logistik dengan menggunakan bantukan software realstatistic dalam Microsof Excel diperoleh keluaran seperti disajikan dalam tabel 2. Menggunakan taraf signifikan 5\%, p-value yang dihasilkan sebesar 0,034 yang artinya model signifikan. Dengan demikian model fit dengan data. 
Tabel 2. Koefisien model

\begin{tabular}{ll}
\hline Chi-Sq & $\mathbf{8 . 6 9 7 5 7 5}$ \\
\hline df & 3 \\
\hline p-value & 0.033594 \\
\hline alpha & 0.05 \\
\hline sig & yes \\
\hline
\end{tabular}

Proses berikutnya adalah mengetahuai bagaimana probabilitas perilaku berkendaraan dari responden dengan melihat variabel-varibel bebas yang diujikan. Hasil luaran perhitungan regresi logistik untuk proses ini disajikan dalam Tabel 3.

Tabel 3. Variabel-variabel perhitungan

\begin{tabular}{lccccc}
\hline & coeff $\boldsymbol{b}$ & s.e. & Wald & p-value & $\boldsymbol{e x p}(\boldsymbol{b})$ \\
\hline Intercept & 9.606304 & 33.78217 & 0.080861 & 0.776134 & 14858.15 \\
\hline Kepemilikan SIM & -0.58779 & 1.150307 & 0.261103 & 0.609363 & 0.555556 \\
\hline Pengetahuan rambu & 1.686399 & 1.243251 & 1.839938 & 0.174958 & 5.4 \\
\hline Pengetahuan marka & -8.50769 & 33.76243 & 0.063497 & 0.801051 & 0.000202 \\
\hline
\end{tabular}

Berdasarkan nilai-nilai yang disajikan dalam tabel 3, dapat diinterpretasikan bahwa:

1. Kepemilikan SIM berhubungan secara negative terhadap probabilitas seseorang untuk berperilaku lalu lintas yang baik. Dari luaran tersebut, setiap kenaikan jumlah pengguna kendaraan yang tidak memiliki SIM maka kemungkinan untuk berperilaku lalu lintas yang tidak baik sebesar 0,588 lebih besar jika dibandingkan dengan pengguna kendaraan yang memiliki SIM.

2. Pengetahuan seseorang akan rambu-rambu lalu lintas berhubungan secara positif dengan probabilitas seseorang untuk berperilaku lalu lintas yang baik. Dengan melihat nilai koefisien $b$, setiap seseorang memiliki pemahaman yang baik tentang rambu akan meningkatkan kesadarannya untuk berperilaku lalu lintas yang baik sbesar 1,686 kali dibandingkan dengan pengguna lalu lintas lain yang tidak paham akan rambu.

3. Pengetahuan akan marka jalan berhubungan secara negatif dengan probabilitas perilaku berlalu lintas yang baik. Pengguna lalu lintas yang tidak memahami dan tidak mengerti tentang marka akan mengakibatkan penurunan perilaku berlalu lintasnya sebesar 8,507 jika dibandingkan dengan pengguna lalu lintas lain yang memiliki pengetahuan tentang marka.

\section{KESIMPULAN}

Pengguna kendaraan bermotor roda dua relatif banyak ditemukan pada kelompok usia remaja. Pengguna kendaraan dalam kelompok usia ini mempunyai kecenderungan untuk belum memiliki Surat Ijin Mengemudi (SIM). Lebih lanjut, kepemilikkan SIM memberikan peluang untuk terjadinya perilaku berlalu lintas yang tidak baik. Selain itu, pengetahuan tentang rambu yang semakin baik akan memberikan peranan terhadap kemungkinan perilaku berlalu lintas yang baik. Pada usia remaja, pengetahuan tentang marka yang rendah memberikan probabilitas munculnya perilaku berlalu lintas yang tidak 
baik. Dengan demikian kepatuhan terhadap peraturan lalu lintas dan pengetahuan memberikan dampak terhadap terciptanya perilaku berlalu lintas yang baik, khususnya bagi remaja.

\section{UCAPAN TERIMA KASIH}

Terima kasih kepada Kolantas Polri yang telah memfasilitasi dana melalui Hibah Traffic Accident Research Center (TARC) tahun 2018 bagi terselenggaranya penelitian ini. Ucapan terima kasih juga ditujukan kepada segenap guru, karyawan, dan siswa SMK YPT 1 Purbalingga.

\section{DAFTAR PUSTAKA}

Depkes RI, 2010, Pusat Data dan Informasi Kementerian Kesehatan RI, Jakarta

Direktorat Jenderal Pendidikan Dasar dan Menengah, 2018, Data Pokok Pendidikan Dasar dan Menengah, http://dapo.dikdasmen.kemdikbud.go.id/sekolah/2637B6E56000886846E4

Evans, Leonard, 2004. Traffic Safety, Science Serving Society, Bloomfield Hills

Field, A 2013, Discovering Statistic using IBM SPSS Statistic, London, Sage Publication Ltd.

Korlantas Polri, 2018, Statistik Kecelakaan, Sistem Informasi Kecelakaan Lalu Lintas, http://118.97.77.160/site/login

Pangestika, S.H., 2016. Analisis Biaya Kecelakaan Pengguna Kendaraan Bermotor Roda Dua Di Wilayah Purbalingga Dengan Metode Gross Output, Fakultas Teknik Unsoed, Purwokerto

Sarwono, S., 2011. Psikologi Remaja, Jakarta, PT Rajagrafindo Persada

Sucha, Matus. 2014. Theories, Objectives, and Methods of Traffic Psychology, Palacky University, Olomouc

Sussman, Josep, Introduction to Transportation System, Artech House Inc., Norwood

Wåhlberg, A., 2011, The Manchester Driver Behaviour Questionnaire as a predictor of road traffic accidents, volume 12 - Issue 1 